\title{
Towards Systems Design for Supporting Enabling Communities
}

\author{
Michael Bieber \\ Information Systems Department, College of Computing Sciences \\ New Jersey Institute of Technology bieber@oak.njit.edu \\ Barbara S. McFall \\ Davis College, Division of Family and Consumer Sciences \\ West Virginia University Barbara.mcfall@mail.wvu.edu \\ Ronald E. Rice \\ Department of Communication \\ University of California, Santa Barbara rrice@,comm.ucsb.edu \\ Michael Gurstein \\ Centre for Community Informatics Research, Development and Training \\ Vancouver, British Columbia, CANADA gurstein@gmail.com
}

\begin{abstract}
"Enabling Communities" enable participants to work effectively towards conducting both collective and individual activities and towards achieving collaboratively identified goals. Our focus is on designing the "systems" that support community members in undertaking the tasks or activities they need or want to do. These systems include processes, technology, information and people. We provide a framework for Supporting Enabling Communities (SEComm) with two major components: (1) Participant Support Systems (PaSS) and (2) Community Participation Levels (CPaL). The proposed framework provides an initial model for thinking about community support for interactions, goals and purposes, at all levels of an Enabling Community. It provides new insight by helping community and ICT designers to focus on people's tasks, and to understand the environmental influences and constraints that hinder or facilitate support for enabling community participants.
\end{abstract}

\section{Motivation}

Successful communities facilitate the active participation of current and potential members. They also enable community members to become more effective, providing opportunities to both realize collective and individual goals and obtain benefits that otherwise would not be possible without such participation. We refer to communities that provide such support as Enabling Communities (or ECs, where "enabling" describes an aspect or quality of effective communities -- i.e., an adjective rather than a verb). Such communities and their systems need to be organized or designed in a way that enables participants to work effectively.

This article promotes a re-thinking of such systems from the perspective of "communities" (as in Community Informatics Systems) instead of the perspective of "organizations" as the central agent for information systems (as in Management Information Systems (MIS) theory and research) (Gurstein, 2000). The development of the SEComm framework begins the process of refocusing the field of Information Systems towards communities, and collaborative decision and design processes. The Supporting Enabling Communities (SEComm) framework contains two components. The Participant Support System (PaSS) component focuses on the systems within ECs and establishes the parameters of potential participant support. The Community Participation Levels $(\mathrm{CPaL})$ component describes the nested and hierarchical influence of various participants within ECs.

We apply a classic systems approach to propose a dozen critical foci from the SEComm framework. The first four define the environmental context shaping the system (norms, goals, constraints, and external systems of influence). The second four envision contributors (people, data, technology, and products/services) to the process/task/activities that form the system and are formed by it. The final four address issues of scale (individual, group, community, organization). The SEComm framework should help individuals analyze and design systems that support ECs as well as explore the criteria for the design of systems that support individuals through their participation in ECs. The framework can help to identify, for any particular community, which actors and stakeholders are relevant; appropriate levels of 
analysis; the kinds of collaboration, influence and participation to support; the types of knowledge, people and technology are to include; the processes or tasks required; and the salient context for implementation (norms/policies, goals/shared purpose, constraints, and environment). Having determined these, community support system (SEComm) components can then be matched to actors, interactions, and levels of community participation.

Section 2 discusses the concept of analyzing and designing communities and community support systems. Section 3 introduces and describes the Supporting Enabling Communities (SEComm) framework and its PaSS and CPaL components. The paper concludes in Section 4 with discussion, related work and future research.

\section{Designing Community Support}

Some communities evolve on their own, forming around a context, an environment, a problem or a set of opportunities and growing as people choose to participate (join or become members) when they find its activities, information or services useful. Other communities are deliberately designed to meet the needs of their participants or stakeholders.

What does it mean to design an Enabling Community? Here community design is a deliberate attempt to guide the introduction and use of activities, information and services in a way that makes a community and its members most effective. In this context, support is deliberately determined (analysis), planned (designed), put into place (implemented), and assessed (adapted over time) so that identified needs are comprehensively responded to and resources are allocated efficiently and effectively. Support thus includes community structures and processes, as well as systems that enable these to function effectively. This section begins by briefly reviewing important aspects of communities. Community and system analysis is discussed next, followed by community and system design.

\subsection{Communities and Systems}

The term "community" refers to: (1) a group of people (2) who share ongoing social interaction (3) with some common ties between themselves and the other members of the group (4) and who share an area (common space) for at least some of the time (Hamman, 1997). For our purposes the "area" shared and the "interaction" may also be understood to include "virtual" communities -- electronically linked individuals with an on-going set of interactions around common interests (Katz et al., 2004). Preece (2000) complements this definition by describing online communities as comprising people, a shared purpose, policies (norms) and the technology "to support and mediate social interaction and facilitate a sense of togetherness."

Communities can be the very center of individual, family, group and employee well-being -- economic, political, and cultural - or they may be only one among a number of occasionally conflicting loyalties and involvements. Community participation may be voluntary (people choosing to participate in community activities or to identify with one community or another) or involuntary (people being required to participate as a function of residence, employer mandate, or other ascribed conditions). In either case, communities have the function of enhancing the well-being of its participants.

Enabling Communities, as with others, can be enhanced and made more pertinent to the interests and concerns of individuals through the judicious use by civic, organizational or voluntary authorities, of information and communication technologies (ICTs). ICT-mediated communities may be solely virtual, with no physical counterpart (i.e., online health support groups, MUDs, MOOs and cross-organizational virtual projects) or (at least partially) in combination with physical communities (i.e., NYC's ECHO system or Santa Monica's PEN) (Hampton \& Wellman, 2000; Hiltz, 1984; Horn, 1998; Katz \& Rice, 2002; Majchrzak et al., 2000; Preece, 2000; Rheingold, 1993; Uncapher, 1999).

Such communities are not only information and communications systems themselves, but clearly rely upon computer-mediated information and communication technology in order to exist. Technology in such cases supports activities, records knowledge, develops organizational and community memory, and facilitates relationships among individuals who have much to share but would not otherwise have known about, or been able to interact with, other community members (Ackerman \& Halverson, 2000; Sproull \& Kiesler, 1991; Stein \& Zwass, 1995).

Community-based, community-driven communication and information systems should provide access to technology-enabled opportunities for all community members (especially the disadvantaged). Many kinds of computer technologies can be conceptualized as providing support for ECs: computer-supported collaborative work systems, group support systems, computer conferencing and computer-mediated communication systems, distribution lists/discussion groups, blogs and wikis, virtual classrooms and distance education, and online community networks.

In a broader sense, beyond ICTs, the systems that support ECs encompass a wide range of components - the environmental context, the participants, information, among others. Such systems require increasingly sophisticated user-focused understanding, design and application, and applied social leadership, entrepreneurship and creativity (Gurstein 2003). Constraints (budgetary, technological, and social) of course exist within every community environment, and the people and systems concerned with community design must deal with these. 


\subsection{Community and Systems Analysis}

Community systems analysis requires a deep understanding of the current state of a community's components (people; structures regarding governance, groups and communication; systems, etc.) and environment (budget, mandates, supporting organizations, legal constraints, etc.), as well as requirements for responding to current and future problems, goals, needs and desires. Thompson and Kinne's (1999) synthesis of community change theories proposes that the following components are interrelated and thus affect development and change efforts: first, the external environment; second, large-scale community aspects such as development and planning, social movements, and vested interests; third, coalitions, advisory groups, and networks; fourth, subsystems of a community organization, such as individuals, leadership, organizations, and organizational development; and fifth, individual beliefs, characteristics, and behaviors. Schuler (1994) proposes that a community network consists of two primary components -- the human context(the on-line community, individual and organizational participants, influencing organizations, the community network organization, and the infrastructure providers), and the technological infrastructure (hardware, software, and delivery channels). The three main activities in such a community analysis are defining the community (boundaries, participants, authorities), collecting new or existing information in collaboration with community members, and assessing the community's capacity (institutions, community actions, community resources, skill levels, advocates).

It is crucial that a broad range of stakeholders (community leaders, everyday community members and supportive organizations) is involved in community and system analysis, as they hold and represent the community knowledge and are the primary resource for knowing what they really want and need. The information systems literature is full of examples where systems have failed because the day-to-day users were not involved in analysis and design (Capaldo et al., 1995; Hirschheim, 1985; Jiang et al., 2001; Johnson \& Rice, 1987; Kujala, 2003; Nelson, 1990).

\subsection{Community and Systems Design}

Equipped with a thorough analysis and its portfolio of requirements, community leaders can begin to design structures and supportive systems that fit (and expand) the community's resources. (This may include reorganization of current structures and systems.) As noted above, community systems include much more than technology; they also encompass the people, knowledge, processes and resulting support. Therefore the design of systems goes beyond the specifications for the appropriate hardware components and software code. System design should specify people's roles (both those participating in the system's activities and those using its resulting outcomes or services); the kinds of data and knowledge that should be acquired, stored and shared; the steps of the processes and activities for accomplishing the system's purpose; and the support that the system requires.

Notions of equity and civil society go hand-in-hand with helping participants become effective within Enabling Communities. The support provided by a community system should be comprehensible and comprehensive, usable and useful to all community members who participate within it, or otherwise interact with it. All participants should have access (as appropriate) to the community's data, information and knowledge in a manner they can understand and utilize. Systems should support all participants in (appropriate) community-related goals. These ideals provide additional goals for system designers and community system researchers. 


\section{The Supporting Enabling Communities (SEComm) Framework}

We now introduce the SEComm framework, consisting of two major components: Participant Support Systems (PaSS) and CPaLs (Community Participation Levels). While we begin this discussion in terms of individual participants, later we will apply the same arguments and resulting design model to support higher-level participants.

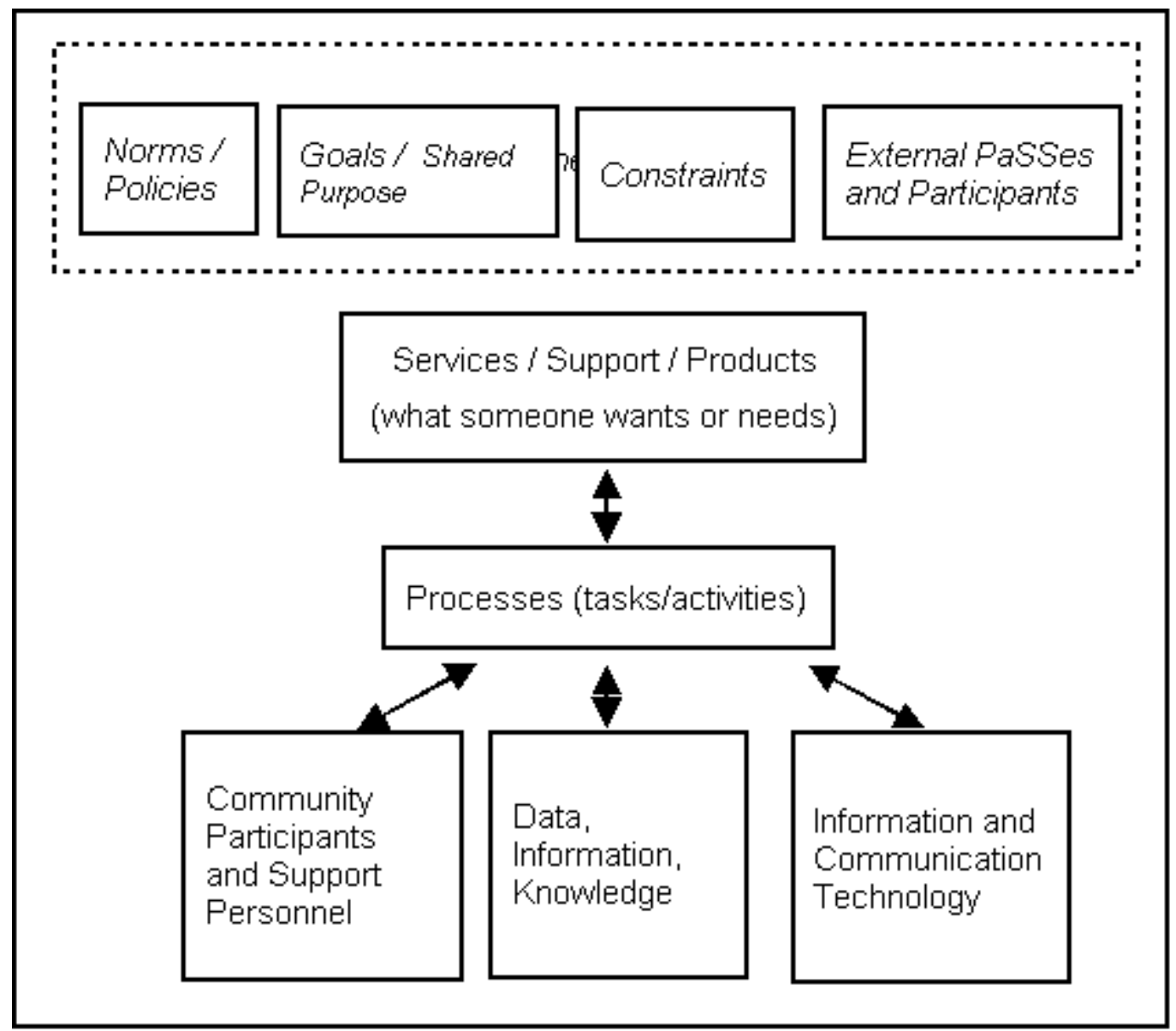

Figure 1. Participant Support System (PaSS) component of the SEComm framework.

Double-headed arrows indicate the interactivity among all components. The environment and context aspects also have the potential to influence every component.

\subsection{Participant Support System (PaSS)}

Figure One presents the "participant support system" (PaSS). At its heart resides the process, or the things that the system does to perform the tasks or activities necessary to enable one or more participants in some way, at a specified level of analysis $(\mathrm{a} \mathrm{CPaL})$. Undertaking the process requires technology, people and information, all acting within an environmental context and constraints. This component is strongly influenced by Alter's model of an information system (Alter, 2006) and the community change model summarized in section 2.2 (Thompson \& Kinne, 1999). The core feature of Alter's model is the work practice or set of tasks that the information system is designed to support. That model includes as a core element, a separate "client" who "receives" the system's output. PaSS however, considers multiple participants within the PaSS, and including actors external to the immediate system, thus including those working within another level or element of a multi-layered and complex community structure, and how they use the resources. PaSS also builds upon Preece's (2000) definition of an online community as being defined by four high-level criteria: people, a shared purpose, policies, and computer systems. People and computer systems are PaSS components, while the shared purpose and policies lie in the PaSS environmental context.

\subsubsection{Processes.}

A process is one or more steps of a task or activity. Processes supported by a PaSS should help a participant to accomplish something they want or need to do within the context of an individual or community goal (Bieber, Engelbart et al., 2002). The process supported may be complex, requiring advanced knowledge and technological support and training, or it may be simple such as looking up a fact on a Web site. It may be formalized or informal, and undertaken individually or collaboratively. To fully participate within or manage the process, people may require directions, assistance, training, consulting, time and support for experimentation, discussions among themselves about possible 
solutions and applications, and both technical and emotional support (Johnson \& Rice, 1987).

Examples of community-motivated processes could include finding collaborators for a project or an activity; developing a community service grant proposal, operating an online community assistance "help desk", building support for a change in a school curriculum, increasing a sense of community participation and identification, or conducting a campaign to become a community official. Equally important and central to community vitality and sustainability are PaSS processes for communication among community members and any other participants (Bowes, 1997; Bracht, Kingsbury \& Rissel, 1999).

\subsubsection{Technology.}

A PaSS does not need to have an ICT component. Many communities in the past or present have excelled without computer technology, relying on their available and learned social technologies. For example, a local support group for a medical condition has all the components of a successful PaSS: participants and perhaps a facilitator; the participants' knowledge and experience; and the societal norms, laws and financial constraints that comprise the local environment. With this effective "social" technology as its base, the physical technology could have been a telephone, snail mail letters, or simply printed notices distributed to local doctors or on bulletin boards in the local area. All are part of the "system" of support.

When used appropriately, technology has the potential to make community processes more efficient and effective, and to enable new types of processes and communities that previously may have been infeasible due to distance or other constraints (Gurstein, 2000). ICTs can expand the number, diversity, and location of the participants in the medical support community, for example (Rice \& Katz, 2001). Online sources can provide information in addition to that available locally and provide information to participants outside of scheduled gatherings. Technology may reduce the monetary and time costs of community activities. It also allows for communication at a distance and thus a much broader range of involvement from community members. Email can reduce the cost of mailings; videoconferencing, online meetings and gaming sessions can reduce the cost of renting a meeting place and travel; online information can be cheaper than purchasing books, and provide access to experts and expertise anywhere in the world. Beyond the obvious and important reduction in costs, new media also allow different kinds of interactions among different kinds of participants, fostering greater awareness of others in a community, their needs, expertise and resources, and overall social capital (Katz \& Rice, 2002).

However, technologies by themselves may not be successfully implemented or used (Gurstein, 2003), and may foster unintended and negative consequences. A simple web-based community suggestion box, for example, may limit the length of a suggestion. So from the community's perspective system, designers are obliged to ensure that the technology being applied or developed is appropriate to support the particular community and process. Environmental constraints or factors such as the amount of time available to investigate options may dictate that the technology chosen is not the most appropriate, but at least is adequate.

\subsubsection{People.}

A PaSS also includes the people who manage its process, those who participate in it, and those who both benefit (and possibly suffer) from it. For example, the people who discuss problems in a chat room, facilitators mediating the discussion, monitors checking the participants and discussion content, and the technicians who design, install and maintain the chat software, all are part of the system. Thus, people are encompassed very broadly in the system definition because of the wide scope of people's roles in community systems and in the life cycle of designing and supporting these systems.

\subsubsection{Providing Products and Services.}

Undertaking a process as described here will for the most part result in some kind of output, service, product or knowledge for the participants. For example, the result of searching for information on a Web site could be considered a service enabled by a process. Facilitating remote collaboration on a research project could be considered a service resulting in an intermediate or final output such as a report, paper, system resource, proposed legislation or social activities. Sometimes community participants can benefit from the outputs of a system without directly being involved in the enabling process. For example, a workgroup in an educational community may use the system to collaborate remotely on developing a set of guidelines for teachers. The teachers who use these guidelines are not (necessarily) part of the specific PaSS process through which the guidelines were developed, but, as community members, they are part of the general PaSS, and should be consulted in the original systems analysis.

\subsubsection{Data, Information and Knowledge.}

Conducting a process may involve the production, consumption or management of some data, information or knowledge -- both by the people and by the technology -- and likely through multiple iterations, revisions, and elaborations. For example, an asynchronous discussion system will maintain data about its registered users for use in 
administering the system, in addition to the content of the discussions (Fukuhara et al., 2003). Bieber, Im et al. (2002) note that "much of a community's knowledge lies within its documents, discussions, decisions...processes, and the awareness by members of other members' expertise ... Community knowledge also includes the links (relationships) among all these elements and documents, including relationships among community members... Collectively this knowledge constitutes a community memory of past experiences, considerations and decisions that knowledge workers, community leaders and other members can explore" (see also van den Hooff et al., 2003).

Data, information and knowledge may be off-line, in books or in people's heads, or it may be maintained online. While some community knowledge is explicit, much is implicit or tacit (Choo, 1995; Nonaka, 1994). Unlike explicit, or objectified, social knowledge, collective knowledge is difficult to identify, organize and make public. Yet by its nature it is inherently a public good - it is not diminished by distribution, can be reapplied within the community, and grows with use and application. Paradoxically, collective knowledge usually has no value when controlled solely by individuals - that is, collective knowledge has its greatest utility when it is widely known and shared, generating social capital (Baron et al., 2000). Thus a central problem for ECs is to make social knowledge widely sharable, foster the development of social capital, and support communities in enabling both their individual members and their collective processes and goals. We consider all relevant explicit and tacit knowledge as potentially part of a PaSS, for these are all resources for performing its processes.

The system can maintain and give access to this information through a broad range of technological support such as "flat files", database systems, knowledge management systems, digital library repositories, information retrieval systems, decision support systems, discussion lists, expert and expertise locators, hyperlinked member profiles, etc.

\subsubsection{Environmental Context.}

Communities have more or less identifiable and enduring norms and policies, and goals and shared purposes (for example, creating services or products, nurturing, sustainability, civic engagement, individual and community independence/empowerment, personal and community development and improvement, as well as generally addressing the reason people participate in the community: to learn, to cope with problems, to socialize). Communities are also subject to a wide variety of constraints and environmental factors, such as budgets and finances, resources, legal constraints, legitimacy and ethics, physical infrastructure, and the political environment regarding information sharing, culture, social systems, and overall communication infrastructure (Bracht, Kingsbury, \& Rissel, 1999; McFall, 2003; Thompson \& Kinne 1999).

The environment influences each of a PaSS's constituent parts by providing the context within which processes are conducted (supported, fostered, altered, suppressed, resisted, etc.). A shared purpose of nurturing children within an educational community will influence the set of processes (services) and types of information provided within that community. A community board might set the goals for a community volunteer or task force, which would then develop or identify which processes must be available to enable the achievement of those goals. The budget could constrain the amount of disk storage, and thus the extent of archived past online discussion comments, available. Laws may constrain the information available to participants, such as filters that must be in place for minors, or the online provision of patient-specific diagnosis and treatment, whether by doctors or laypeople (Rice \& Katz, 2001).

How a PaSS is designed, in turn, can influence the environment. For example, during the design phase, aspects of the environment could be made explicit (such as what resources truly would be allocated by the sponsors, or the community's current privacy policy). The final design may have the effect de facto of setting policies, such as how a privacy policy is implemented or what permissions are necessary to undertake a particular action. Blocking access to certain information for some participants (e.g., excluding minors from sites discussing reproductive issues for example) conceivably could spark a discussion of censorship that propagates into the larger society and results in new legislation or greater economic constraints for some level (such as public libraries). Such policies could have unexpected influence and consequences within or across community levels (within the CPaL sub-framework -- see section 3).

\subsubsection{Interaction between Design and Technology as Community Enablers.}

The implemented design of a PaSS will influence how and whether participants perform tasks and activities, either by built-in structures, administrator- or user-set changes in system parameters, agreed-upon online norms, emergent social conventions, etc. By accident or on purpose, it may fix the number or authority level of participants in a decision, determine how easily people can update information, determine the degree to which people have the ability to lurk, dictate how easily people can start a discussion that is off-topic, and so on. Thus a PaSS should provide and require ongoing evaluation and feedback, so that system support will evolve towards being more appropriate and better matched over time and under different environmental conditions, and as interactions across CPaLs increase (see below). 
Environment:

The environment contains the external participants and systems, which can reside at the different community levels described in section 3.2. The technology can facilitate and structure information-sharing among participants and systems (e.g., through Web sites, discussion forums and shared data). Alternatively a rigid structure or lack of technology may hinder communication.

The environment also contains the various policies described in the categories below, which guide the process, how people should participate, how the data should be analyzed, and what technology should be available. If designed properly, the technology could play a role in supporting and communicating these policies, as well as providing background information such as that concerning community norms. Poorly designed programs may not be able to support the policies or may allow people to get around them.

Process:

The voting process can model various policy directives, which software might support, hinder or not influence.

The process can enforce that voting be mandatory, entirely optional, or require that a minimum number of members vote. It could be anonymous or with identities known. Group or community members may be required to read certain discussion comments or background material before voting. Voters may be permitted to see the vote subtotals while voting is underway, or this could be hidden.

Purchased software however may obstruct the desired process. It may, for example, only permit anonymous voting, or it may leave anonymity as an option. Software could be constructed to prohibit someone from voting until they have viewed all relevant discussion comments; otherwise the community would have to rely on the honor system. Software might include a feature to display vote subtotals, (and provide technicians with the option to disable this function).

\section{People:}

Community policy should determine who can vote in working group or community-wide decisions (including opinion gathering). Technology could limit the voting to registered members. To encourage lurking and other forms of "light participation" forums, community sites might not require users to log in. But the software may restrict voters to those who have logged in.

\section{Data:}

The community may wish to view statistics about votes based on demographic information about members, assuming this data is maintained and the software has an analysis functionality. Privacy and legal requirements concerning the data will need to be applied.

Systems may display discussion or voting data anonymously, but keep track of which users entered which comments or votes so that users can receive confirmation of, and review their participation. System technicians have an ethical obligation not to share this information, but whoever owns the system also owns this confirmation data and has the legal right to use it (at least in the United States).

Similarly, systems providing anonymity but requiring users to $\log$ in routinely maintain a log of all user actions in order to track system malfunctions. Again, despite ethical concerns, whoever owns the system also owns this debugging data and has the legal right to use it.

Technology:

Many of the technological issues are discussed in the other categories. Another current concern is security. A system technician or hacker may have the skill to "rig votes," i.e., to alter the data or the system procedures. This is a major concern with both electronic voting machines and national e-voting schemes (Gritzalis, 2003). 
Of course, not all community members may have access to the community system when and where they need it. Furthermore, poorly designed interfaces (screens) may prevent members from using it effectively. Technology, as well as the environment and people, affects what is accessible and how it is accessed (Gurstein, 2003; Rice et al., 2001).

As an example, Table One illustrates how a PaSS design might facilitate or constrain voting. Voting software can support both working groups and entire communities in their decision-making. The decision being voted upon could be a budget resolution, an election, or a logo for the community's website. Voting could be used to gather opinions or be binding in deciding an issue. In all of these cases, the community, perhaps through the system itself, could decide on who would be involved in the voting -- just the members of the working group, other aggregations of individuals, and all the way up through to the community as a whole.

\subsection{Community Participation Levels (CPaLs)}

Where are the boundaries of a PaSS system and who are its participants? The second SEComm component, Community Participation Levels (CPaLs), identifies four primary levels at which participation and collaboration takes place -- individual, group, the community itself, and the organizations supporting the community -- and the influence each has on the others. Participant configurations occur within and across these levels. Each PaSS is a system supporting participants at one or more of these levels, and supporting communication within and between the levels, for one or more specific, related processes. While the actual users, of course, are all individuals (or perhaps intelligent agents), a PaSS can be designed as a support in their tasks as individuals, as members of a group in their group activities, as individual members or groups in community-wide functions, or as individuals and groups at the organizational level in their efforts in support communities.

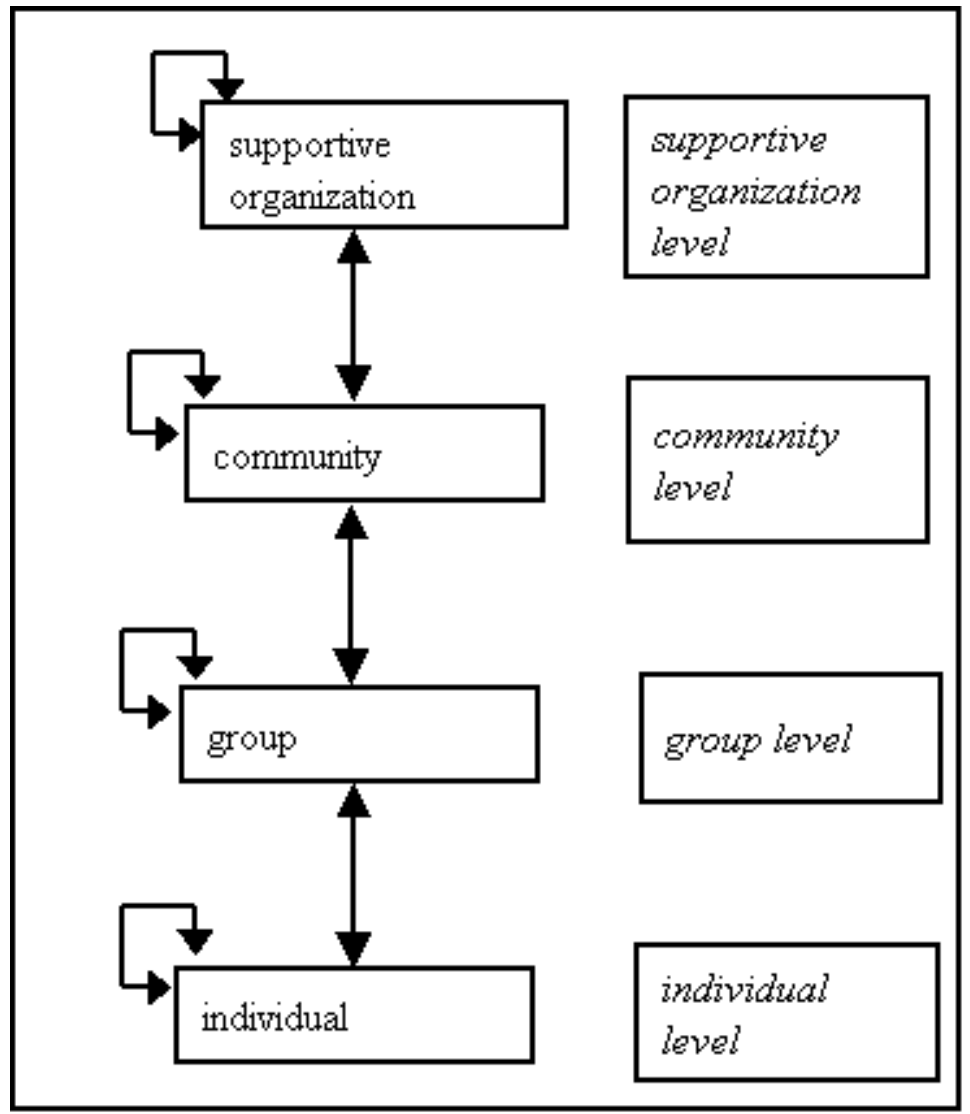

Figure 2. Community Participant Levels (CPaL) component of the SEComm framework.

$\mathrm{CPaL}$ positions each community system or PaSS within these levels and makes its corresponding collaborations and influence flows explicit. Arrows represent both the influence flows that correspond to the system's environmental context from the PaSS model and collaboration among participants in other systems and levels. Influence flows are between systems at the same or different levels. Collaboration also may be among participants at the same or different levels.

Figure Two depicts the SEComm framework's community participation levels. Arrows indicate flows of influence among levels, as well as the patterns of informal or formal collaboration and associations within levels. Influence is an environmental concept, whereas collaboration refers to the boundaries encompassing the participants of a PaSS (or multiple PaSSes, perhaps with overlapping components). Generally a PaSS will be designed to support the collaboration of specific (types, groups and levels of) participants, so by definition its scope (boundaries) will encompass them. 
A fine line exists between active collaboration and influencing the people "external" to a system (e.g., by sharing information with them). It is up to community analysts and designers to define the scope (boundaries) in a way that best supports the primary participants in specific activities. The SEComm framework provides direction for enabling the different levels of community participation, each with different actors and forms of interaction, to be matched with the capabilities and affordances of appropriate PaSS processes and technologies.

Thus the overall Enabling Community Systems can be conceived as a series of nested PaSSes ranging from smallest to largest, reflecting the four community participation levels. Importantly, for this discussion, systems theory holds that higher-order systems emerge from and subsequently govern lower-order systems (see Banathy, 1996; von Bertalanffy, 1968; Boulding, 1956). This hierarchy defines the bi-directional lines of collaboration and influence among the various levels.

The environment can affect the shared purpose, goals, norms, policies and constraints of a given participant and PaSS, including the system's component parts -- processes, people, information and technology. Influence from a higher to a lower level could include providing goals, constraints, structure, resources, feedback, governance, or information for knowledge-sharing and learning. Conversely, the participant and the PaSS can influence the environment. Influence from a lower to a higher level includes providing information, opinions, policy advice, decisions and other knowledge, resistance, and the use of resources perhaps owned or controlled by the higher levels. Often initiating, encouraging, and fostering this influence from lower to higher level is one of the system's goals. The framework highlights that each community level has the potential to influence the other.

\subsubsection{Individual Level.}

The discussion so far has focused primarily on enabling individual community members to do the kinds of things they want or need to do to achieve their goals within the community context. Thus many of the PaSSes discussed primarily served the particular tasks of individuals as individuals. These include one-person tasks, such as looking up information on a Web site or having a help desk or medical expert answer a question individually. Once individuals begin to collaborate for the purpose of support, the framework comes to treat this as an informal or formal group. The PaSS that supports their working together therefore would be modeled at the "group level."

\subsubsection{Group Level.}

Virnoche and Marx (1997) argue that community must comprise "individual identification of and involvement in a network of particular associations" (i.e., groups and alliances). Collaboration within a single level could include working together on a project; knowledge-sharing and learning; making decisions through a variety of processes, such as voting or consensus building; or socializing. Individuals can collaborate with other individuals informally, as people playing a game or chatting, or in formal groups, such as committees or a student council. Collaboration techniques and computer-supported collaborative work (CSCW) and other "groupware" tools could be embedded in the process to support facilitation, brainstorming, version control, knowledge management, and/or anonymity (Majchrzak et al., 2000; van den Hooff et al., 2003).

Two or more groups could also choose to collaborate informally or formally. For example, two committees working within the same community could be tackling similar problems such as increasing membership and bettering public relations and have the need to coordinate budgets. Groups also may form subgroups around particular issues or interests and have the need for such technology supports as computer conferencing, threaded newsgroups or participant awareness features (Alavi \& Tiwana, 2002; Haythornthwaite, 2002).

Groups may even form informal or formal alliances. For example, membership committees within separate communities could form an association of membership committees to discuss common issues. Sometimes such an association could be considered as a community in its own right, such as a "community of practice" of people and groups interested in membership issues (Brown \& Duguid, 1991; Lesser et al., 2000; Wenger et al., 2002). In this case the supporting PaSS would be at the "community level" of this framework. Whether one would consider a particular set of participants to be at the group or community level is fairly subjective, and depends on how useful it is to conceptualize the participants as a group within a larger community or not.

\subsubsection{Community Level.}

The community as a whole will have tasks that it needs to accomplish (within the framework of its constitutive associations and networks) in order for it to achieve the goals that its participants have set for it and to ensure that its internal formal (or informal) structuring and processes function effectively. These activities can include local governance, such as running a conference or meetings for knowledge sharing or socializing; undertaking (and legitimizing) decision-making processes; developing processes for managing and influencing changes in the broader political social and economic environment; or overall management of community resources and activities (Figallo, 1995; Gurstein, 2000; Hampton \& Wellman, 2000; Keeble \& Loader, 2001; Schuler, 1994; among others). 
Two or more communities could choose to collaborate informally or formally. Many communities may wish to coordinate their protests about larger institutional or social issues. A well-designed PaSS could make these protests more effective, or the dialogue between protesting communities and institutions more collaborative and productive, aiming at larger collective benefits (Rheingold, 2003). Communities may form informal or formal alliances (Hampton \& Wellman, 2000). Often communities will form subgroups to work together, in which case one would consider the supporting PaSS for that subgroup to be at the "group level" of this framework.

\subsubsection{Supportive Organization Level.}

A community may be supported by one or more organizations including educational institutions, private companies, governmental bodies or non-governmental organizations. Formal or informal collaborations or alliances could also exist among such organizations. For example, traditional competitors could use organizational and network systems to form a "community of practice" to develop new designs or systems beyond the competence of any single organization (see Majchrzak et al., 2000) Also, a PaSS could facilitate a supportive organization or alliance of supportive organizations in its relationship with the communities. For example the ACM professional society, which is the umbrella organization supporting many different special interest groups, provides an extensive support structure for community officers (such as training and regular meetings) as well as publishing facilities for community publications.

The focus at this level again is relative. The $\mathrm{CPaL}$ component would position PaSSes supporting, for example, community sponsorship at the "supporting organization" level. However, when an alliance of organizations gets together, that alliance could be considered as a formal or informal community in its own right, with its own set of working groups. The importance of $\mathrm{CPaL}$ is less in the precision of system categorization than in providing a tool for community analysts and designers to become more aware of the different influences and collaborations that take place within and around their community.

\section{Discussion}

\subsection{Implications for Community Informatics System Design}

The SEComm framework provides a useful means to order what are otherwise quite complex and disparate bases for analysis. The SEComm framework also provides a useful addition to the "effective use" framework (Gurstein, 2003) by deconstructing from a community perspective the process of systems conceptualization and design, beginning the longer term process of making the effective use model a more operational basis for systems design and development.

\subsection{Future Research Opportunities}

The SEComm framework presents many opportunities for future research. Primary among these would be further research into the efficiency and effectiveness of the framework in field applications, as well as considerations of the ethical and moral implications surrounding design and implementation. The framework does not explicitly address community governance, the promotion of local independence and self-determination, or improving the quality of life for members. Moreover it does not address issues of equity or the broader questions of equity and civil society. Incorporating these aspects into the framework explicitly could help community analysts understand them better and community system designers actively incorporate them into their designs.

For designing PaSSes that truly enable participants, we also need a deeper understanding of the participants in context and their wants and needs (McFall, 2006; McFall et al., 2006). Who participates in communities and who would participate if they had appropriate access? What do participants want and need to do (tasks, activities and processes), as individuals looking to support -- and benefit from -- community participation? Enumerating and classifying the types of possible norms, policies, goals, shared purposes and constraints (environmental factors) would make these aspects explicit. This would help analysts and designers realize which factors (positively and negatively) affect the systems they are designing (or just analyzing to understand) and account for them more effectively.

Determining these factors most likely will require both theoretical grounding in frameworks of individual, organizational and community needs, as well as empirical study. Once we have a solid classification of processes/tasks and their characteristics, future research should determine which technologies best support which tasks and activities, or the need for entirely new classes of processes and ICT solutions. It may turn out that technologies and approaches developed in other fields (e.g., for knowledge management or computer supported collaborative work) may prove very useful for fulfilling these requirements.

This article describes the SEComm framework in terms of single systems. Multiple systems support different aspects of a community and these systems intersect in a multitude of ways. Many systems can be viewed as subsystems of the larger community system. For each subsystem, the boundary can be drawn (by definition) at a useful and functional level. The surrounding systems can influence or be influenced. They can provide resources (knowledge, technology, people and processes) or utilize the same resources, perhaps at the same time (and perhaps compete for them). Future research should explore ways that SEComm can better make this complexity explicit for community 
designers. Finally, analyzing tensions and interactions across community levels would provide greater understanding of successful and failed community systems.

\subsection{Closing Thoughts}

While community researchers have made great strides in understanding aspects of a successful and sustainable community, on the whole we still do not fully understand how to design and integrate community systems effectively. The proposed SEComm framework (the PaSS and CPaL components) provides an initial model for thinking about community support for various kinds of interactions, and for various goals and purposes, at all levels of an Enabling Community. It should help community and ICT designers to focus on the things that people want and need to do, and to understand the environmental influences and constraints that hinder or facilitate support for enabling community participants at all levels.

\section{References}

Ackerman, M.S., \& Halverson, C. (2000). Reexamining organizational memory. Communications of the ACM, 43(1), 58-64.

Agres, C., Edberg, D., \& Igbaria, M. (1998). Transformation to virtual societies: Forces and issues. The Information Society, 14(2), 71-82.

Alavi, M., \& Tiwana, A. (2002). Knowledge integration in virtual teams: The potential role of KMS. Journal of the American Society for Information Science and Technology, 53(12), 1029-1037.

Alter, S. (2006). The work system method: Connecting people, processes and IT for business results. Larkspur, CA: Work System Press.

Banathy, Bela. H. Sr. (1996). Designing social systems in a changing world. New York: Plenum Press.

Baron, S. Field, S., \& Schuller. T. (Eds.). (2000). Social capital: Critical perspectives. Oxford, UK: Oxford University Press.

Bieber, M., Engelbart, D., Furtua, R., Hiltz, S.R., et al. (2002). Towards virtual community knowledge evolution. Journal of Management Information Systems, 18(4), 11-36.

Bieber, M., Im, I., Rice, R. E., Goldman-Segall, R., et al. (2002). Towards knowledge-sharing and learning in virtual professional communities. In Proceedings of $35^{\text {th }}$ annual Hawaii International Conference on System Sciences (HICSS '02) (vol 8., p 213b), Hawaii, January.

Boulding, K. E. (1956). General Systems Theory: The skeleton of science. Management Science, 2, 197-208.

Bowes, J. E. (1997). Communication and community development for health information: Constructs and models for evaluation. Review prepared for the National Network of Libraries of Medicine, Pacific Northwest Region, Seattle. Seattle, WA: University of Washington, School of Communication.

Bracht, N., Kingsbury, L., \& Rissel, C. (1999). A five stage community organization model for health promotion: Empowerment and partnership strategies. In N. Bracht (Ed.), Health promotion at the community level: New advances (2 ${ }^{\text {nd }}$ ed., pp. 83-104). Thousand Oaks, CA: Sage.

Brown, J., \& Duguid, P. (1991). Organizational learning and communities of practice: Toward a unified view of working, learning, and innovation. Organization Science, 2, 40-57.

Capaldo, G., Raffa M., \& Zollo, G. (1995). Factors influencing successful implementation of computer based technologies in knowledge-intensive activities. Information Resources Management Journal, 8(4), 29-36.

Choo, C.W. (1995). Information management for the intelligent organization: the art of scanning the environment. Medford, NJ: Information Today, Inc.

Figallo, C. (1995). The WELL: A regionally based online community on the Internet. In B. Kahin, \& J. Keller (Eds.), Public access to the Internet (pp. 49-61). Cambridge, MA: The MIT Press.

Fukuhara, T., Chikama, M., \& Nishida, T. (2003). Supporting an experiment of a community support system: Community analysis and maintenance functions in the public opinion channel. In M. Huysman, E. Wenger, \& V. Wulf (Eds.), Communities and technologies (pp. 347-367). Dordrecht, The Netherlands: Kluwer Academic Publishers.

Gritzalis, D. (Ed.). (2003). Secure electronic voting. Boston, MA: Kluwer Academic Publishers.

Gurstein, M. (2000). Community informatics: Enabling communities with information and communications technologies. Hershey, PA: Idea Publishing Group.

Gurstein, M. (2003). Effective use: A community informatics strategy beyond the digital divide. First Monday, December 2003. http://www.firstmonday.dk/issues/issue8 12/gurstein/index.html 
Hamman, R. (1997). Introduction to virtual communities research. Cybersociology Magazine, 1(2). http://www.socio.demon.co.uk/magazine/2/is2intro.html

Hampton, K., \& Wellman, B. (2000). Examining community in the digital neighborhood: Early results from Canada'swired suburb. In T. Ishida, \& K. Isbister (Eds.), Digital cities (pp. 475-492). Heidelberg, Germany: Springer-Venlag.

Haythornthwaite, C. (2002). Strong, weak, and latent ties and the impact of new media. The Information Society, 18(5), 385-401.

Hiltz, S. R. (1984). Online communities: A case study of the office of the future. Norwood, NJ: Ablex Publishing.

Hirschheim, R. (1985). Office automation: A social and organizational perspective. New York: Wiley.

Horn, S. (1998). Cyberville: Clicks, culture, and the creation of an online town. New York: Warner Books.

Jiang, J., Klein, G., \& Discenza, R. (2001). Information system success as impacted by risks and development strategies. IEEE Transactions on Engineering Management, 48(1), 46-55.

Johnson, B., \& Rice, R. E. (1987). Managing organizational innovation: The evolution from word processing to office information systems. New York: Columbia University Press.

Katz, J.E., \& Rice, R.E. (2002). Social consequences of Internet use: Access, involvement and interaction. Cambridge, MA: The MIT Press.

Katz, J. E., Rice, R. E., Acord, S., Dasgupta, K., \& David, K. (2004). Personal mediated communication and the concept of community in theory and practice. In P. Kalbfleisch (Ed.), Communication and community: Communication yearbook (vol. 28, pp. 315-371). Mahwah, NJ: Erlbaum.

Keeble, L., \& Loader, B. (Eds.). (2001). Community informatics: Shaping computer-mediated social relations. London: Routledge.

Kujala, S. (2003). User involvement: A review of the benefits and the challenges. Behavior and Information Technology, 22(1), 1-16.

Lesser, E., Fontaine, M., \& Slusher, J. (Eds.). (2000).Knowledge and communities. Boston: Butterworth Heineman.

Majchrzak, A., Rice, R.E., Malhotra, A., King, N., \& Ba, S. (2000). Technology adaptation: The case of a computersupported inter-organizational virtual team. MIS Quarterly, 24(4), 569-600.

McFall, B. S. (2003). Future promise: Designing personal resource systems management as a platform for quality of living and learning. Unpublished doctoral dissertation. Saybrook Graduate School and Research Center, San Francisco, $C A$.

McFall, B. S. (2006). Qualities of living: A platform for practice. East Lansing, MI: Kappa Omicron Nu.

McFall, B. S., Beacham, C. V., \& Shambaugh, N. (March-April, 2006). Personal resource systems management Coordinates for learner-centered technology development in Educational Technology, 46(2), 39-42.

Nelson, D. (1990). Individual adjustment to information-driven technologies: A critical review. MIS Quarterly, March, 79-98.

Nonaka, I. (1994). A dynamic theory of organizational knowledge creation. Organization Science, 5(1), 14-37.

Preece, J. (2000). Online communities: Designing usability, supporting sociability. Chichester, England: John Wiley.

Rheingold, H. (1993). The virtual community: Homesteading on the electronic frontier. Reading, MA: Addison Wesley.

Rheingold, H. (2002). Smart mobs. Cambridge: Perseus.

Rice, R. E., \& Katz, J. E. (Eds.) (2001). The Internet and health communication: Expectations and experiences. Thousand Oaks, CA: Sage.

Rice, R. E., \& Katz, J. E. (2002). Social consequences of Internet use: Access, involvement and interaction. Cambridge, MA: The MIT Press.

Schuler, D. (1994). Community networks: Building a new participatory medium. Communications of the ACM, 31(1), 39-51.

Sproull, L., \& Kiesler, S. (1991). Connections: New ways of working in the networked organization. Cambridge, MA: MIT Press.

Stein, E., \& Zwass, V. (1995). Actualizing organizational memory with information technology.Information Systems Research, 6(2), 85-117.

Thompson, B., \& Kinne, S. (1999). Social change theory: Applications to community health. In N. Bracht (Ed.), Health promotion at the community level ( $2^{\text {nd }}$ ed., pp. 29-46). Thousand Oaks, CA: Sage.

Uncapher, W. (1999). Electronic homesteading on the rural frontier: Big Sky Telegraph and its community. In MA. Smith, \& P. Kollock (Eds.), Communities in cyberspace, pp. 264-289. London: Routledge. 
Van den Hooff, B., Elving, W., \& Meeuwsen, J. (2003). Knowledge sharing in knowledge communities. In M. Huysman, E. Wenger, \& V. Wulf (Eds.),Communities and technologies (pp. 119-141). Dordrecht, The Netherlands: Kluwer Academic Publishers.

Virnoche, M. E., \& Marx, G. T. (1997). 'Only Connect'-E.M. Forster in an age of electronic communication: Computer-mediated association and community networks. Sociological Inquiry, 67(1), 85-100.

von Bertalanffy, L. (1968). General System Theory: Foundations, development, applications. New York: Braziller.

Wenger, E., McDermott, R., \& Snyder, W.M. (2002).Cultivating communities of practice. Boston: Harvard Business School Press. 